\title{
Metáforas corpóreas em design de interfaces digitais
}




\section{O guardador de rebanhos, IX}

\section{Fernando Pessoa}

Sou um guardador de rebanhos.

O rebanho é os meus pensamentos

E os meus pensamentos são todos sensações.

Penso com os olhos e com os ouvidos

E com as mãos e os pés

E com o nariz e a boca.

Pensar uma flor é vê-la e cheirá-la

E comer um fruto é saber-lhe o sentido.

Por isso quando num dia de calor

Me sinto triste de gozá-lo tanto.

E me deito ao comprido na erva,

E fecho os olhos quentes,

Sinto todo o meu corpo deitado na realidade,

Sei a verdade e sou feliz.

\section{INTRODUÇÃO}

Nas últimas décadas a cognição corpórea se estabeleceu como novo modelo para a compreensão do sistema de raciocínio humano. Segundo esse modelo, a natureza da mente humana é corpórea (embodied) ou seja, nosso sistema cognitivo está situado em um órgão vivo conectado a um corpo (também vivo) que está imerso em um ambiente no qual atua. Esta visão contraria os modelos tradicionais que viam nossa mente como um sistema de processamento de informações centralizado onde os órgãos sensório-motores serviriam apenas como um sistema periférico de entrada, saída e transporte de informações para uma central cognitiva abstrata.

O modelo corpóreo concebe que nossas estruturas de conhecimento e nossos mecanismos de criar significados emergem da 
nossa experiência corporal e sensível e de interação com o mundo externo. $O$ conceito de mente corpórea vem da visão ecológica e fenomenológica das ciências cognitivas proposto inicialmente por Varela mas que tem também raízes na ótica de Gibson e Merleau Ponty e nas visões de Piaget e Vygotsky onde é da ação que nasce nossa consciência (Amin et al., 2015; Dongo, 1995; Gibson, 1979; Merleau-Ponty, 1976; Varela et al., 1992).

Por outro lado (Amin et al., 2015) nos explica que à partir do paradigma da mente corpórea, experimentos em neurociência e cognição têm descoberto que as imagens mentais dependem dos mesmos mecanismos cerebrais usados para a percepção e ação. Conceitos abstratos são, portanto, modelizados por nossas estruturas cognitivas em termos de generalizações das experiências sensório motoras chamadas de Image 
Schemas. Este mapeamento foi chamado de metáforas conceituais (conceptual metaphors) por Lakoff \& Johnson que sugerem que esses esquemas de imagem são a origem de nossa compreensão de conceitos abstratos e fundamentam nosso uso da linguagem. Em seu livro "Metaphors we live by" Lakoff \& Johnson discutem esse modelo e propõem uma categorização dessas metáforas corpóreas que será apresentado mais adiante neste artigo.

Atualmente um grande número de pesquisadores concorda como esse paradigma da influências das atividades perceptivas e motoras na construção do nosso entendimento que serve hoje de suporte conceitual para a investigação de suas possíveis aplicações em áreas da ciência cognitiva mas também em Inteligência artificial, robótica, educação (Anderson, 2007; Farina, 2020; Manches et al., 2020, 2020; Shapiro \& Stolz, 2019)e nas área de Interação Homem Computador (Antle et al., 2009b; Bakker et al., [s.d.]; Blackwell, 2006; Gibbs Jr \& Macedo, 2010; Hurtienne \& Israel, 2007).

Neste artigo nos interessamos pelas possíveis interações desse modelo teórico com as práticas criativas do design e como as metáforas conceituais de Lakoff \& Jonhson estão sendo adotadas pela comunidade de Interação Homem Computador. Apresentamos 
também alguns exemplos de tarefas em ambientes digitais traduzidas por meio dessas metáforas como parte de nossa investigação sobre as formas de traduzir em significados os mecanismos cognitivos por trás das metáforas conceituais. Apresentamos finalmente uma ferramenta baseada em cartas físicas que pode enriquecer técnicas de criatividade e geração de alternativas em ambientes criativos e de desenvolvimento de estilos e técnicas de interação em equipes de criação de produtos digitais.

\section{A COGNIÇÃO HUMANA E O PENSAMENTO CORPORIFICADO}

Jean Dortier, em seu livro o cérebro e o pensamento (Dortier, 2011) nos explica que $o$ ato de conhecer mobiliza uma série de processos mentais que permitem aos humanos (mas também aos animais ou certas máquinas) de decifrar seu ambiente e resolver problemas por meio de vários mecanismos cerebrais. "Cognição" é o conhecimento em todas as suas formas e processos: percepção, aprendizagem, memória, linguagem, inteligência, atenção, consciência. $O$ estudo da cognição abrange várias disciplinas e muitos campos de aplicação onde psicólogos, neurocientistas, mas também filósofos e cientistas da computação buscam entender esses mecanismos que regem o funcionamento do nosso cérebro.

Os modelos ditos conexionistas ou computacionalistas sugerem que a percepção, a cognição e as estruturas neurais são mecanismos independentes (Fodor, 1975, 2001) e, sobretudo, que tinham uma relação indispensável com o meio e o estímulo externo. Francisco Varella, no entanto, ousa introduzir a biologia nos estudos sobre cognição e seu trabalho em colaboração com Maturana introduz um modelo dinâmico do sistema cognitivo e perceptivo que depende e existe apenas através de nossa condição de estar vivo corporificado em um corpo que interage com o ambiente externo (Richelle et al., 1994). Nessa perspectiva, é possível concluir que nosso raciocínio não é mais concebido como um conjunto de funções lógicas-abstratas e tratadas como por uma central, mas como um sistema biológico enraizado na experiência corporal e interconectado com as 
estruturas fisiológicas e seus mecanismos de ação e interação com o meio ambiente e outros indivíduos.

Dortier em seu artigo "com que se parece o conceito de cachorro?" vai além ao dizer que "A ideia de cognição incorporada começa com a compreensão de que nosso cérebro é um órgão vivo conectado a um corpo (também vivo) e está imerso em um ambiente no qual atua. Essa inscrição corporal, viva e ativa do cérebro tem um grande impacto no pensamento (no sentido amplo de "cognição"). Isso significa que todas as ideias que nos passam pela cabeça - "limão", "cachorro", "ano", "mãe”, "deus", "liberdade", têm um componente corporal vindo de nosso sistema perceptivo, emocional ou motor" (Dortier, 2010)

Dortier ainda resume em seu artigo que é fácil demonstrar esse ponto de vista com noções concretas como a de um limão. Basta fechar os olhos e pensar em um limão para que a imagem mental, dotada de diversos conteúdos perceptivos como a forma oval do limão ou sua cor e até mesmo suas características de sabor ácido ou as texturas de sua pele, apareçam em nosso espírito.

"Finalmente, dependendo se você gosta ou não dessa acidez (alguns gostam, outros não), a imagem mental associada irá provocar uma reação de atração ou repulsão. Isso é ainda mais verdadeiro no caso da ideia de cachorro. Ele é primeiro representado mentalmente de forma pictórica (com suas pernas, orelhas, cauda e boca), mas sua representação também contém uma dimensão emocional. Para alguém que tem fobia de cães, sua representação mental será associada a uma reação negativa. Se, ao contrário, estamos acostumados a conviver com cachorrinhos simpáticos, a ideia de cachorro vai evocar outros sentimentos: afeto ou lealdade. Resumindo, as ideias são formas, cores, cheiros e colorações emocionais: positivas ou negativas, agradáveis ou desagradáveis (que correspondem às características percebidas e sentidas). Esta é a ideia central de "cognição corpórea" (Dortier, 2010)

O paradigma da cognição corpórea como descrito por Valérie Buron (Buron, 2014) é portanto a ideia de que a cognição é primeiro corporificada, ou seja, que leva em consideração o fato de que cada espécie evolui em seu próprio mundo com suas próprias regras. Nossas diferentes capacidades são, portanto, inseparáveis de nosso corpo, mas também de nossa linguagem e nossa história cultural. Assim toda a atividade cognitiva sensório-motora faria parte de uma interação física com o meio ambiente da qual emergem conceitos que nos permitem dar sentido ao nosso mundo. 


\section{METÁFORAS DA COGNIÇÃO CORPÓREA}

A emergência destes conceitos provenientes de nossa interação sensório-motora com o mundo fez surgir uma outra teoria apresentada por Lakoff \& Johnson no livro "Metaphors we live By". Esta abordagem está sobretudo relacionada à linguagem e à nossa forma de descrever e discursar sobre o mundo por meio de metáforas. A ideia de cognição corpórea traz à tona nosso corpo como única interface com o mundo, e que isso tem um grande impacto no nosso pensamento (no sentido amplo de "cognição"). Assim como citado anteriormente por Dortier, isso significa que todas as ideias que passam pela nossa cabeça - "limão", "cachorro", "ano", "mamãe", "Deus", "liberdade" têm um componente corporal estimulado por nosso sistema perceptivo, emocional ou motor.

Uma das consequências dessa teoria é relativa à nossa capacidade inata de construirmos mapeamentos metafóricos entre as ideias abstratas e as estruturas mentais moldadas a partir de nossa experiência perceptiva. As ideias têm formas, cores ou podem ter um gosto bom ou ruim. Essa visão integrada sobre a influência da atividade perceptual e motora no sistema cognitivo humano se aplica não apenas às ideias de objetos e pessoas reais, mas também a conceitos abstratos como no uso de metáforas pela literatura.

Lakoff e Johnson argumentam assim em seu livro "metaphors we live by" (Lakoff \& Johnson, 1980) que as metáforas não são o resultado de um refinamento da criação humana mas surgem de um mecanismo natural para que nossas mentes possam lidar com conceitos abstratos. Nós naturalmente construímos correspondências entre os conceitos abstratos como liberdade ou amor com nossa experiência concreta dos sentidos como dor, calor e frio. Essas correspondências criam estruturas cognitivas chamadas de Image Schemata e nós as transcrevemos nos que os autores chama de metáforas conceituais também chamadas por outros autores de metáforas corpóreas.

Assim a visão contemporânea de Lakoff e Jonhson questiona a 
metáfora como uma sofisticação intelectual ou poética. Eles sugerem que o uso de metáforas é um mecanismo constante em nosso sistema conceitual e pontuam nossa vida diária comunicativa e racional como uma capacidade humana natural de corresponder a conceitos abstratos como "Amor" ou "Justiça" com emoções, e outras correspondências retirados de nossas relações experienciais diárias, orientações espaciais, objetos, substâncias e relações socioculturais (religião, política, etc.).

Em seu livro Lakoff e Johnson estruturam e categorizam esse mecanismo em padrões de correspondências (mapeamentos) em domínios de experiência e padrões de conceito criando grandes conjuntos de metáforas corpóreas. Conceitos, como relações de proximidade e de distância, orientações espaciais (para cima, para baixo, frente, atrás), mas também nossa relação com objetos, substâncias e nossas relações socioculturais. Esses princípios gerais seriam estruturados em termos de áreas mais amplas de experiência. Eles listam essas metáforas em 3 grandes grupos (figura 1):

Metáforas estruturais: casos em que um conceito é metaforicamente estruturado em termos de outro. (Tempo é dinheiro, discussão é guerra).

Metáforas orientacionais: Um conceito metafórico que estrutura todo um sistema de conceitos. Como a maioria deles tem a ver com orientação espacial, eles são chamados de orientacionais. (Conceitos positivos estão para cima, conceitos negativos como o inferno baixo, de dentro para fora, $\mathrm{O}$ futuro está à frente, ruim é longe).

Metáforas ontológicas: conceitos estruturantes baseados em nossa experiência com objetos físicos e substâncias (o tempo flui, um personagem frágil, uma pessoa sem limites). 


\begin{tabular}{|c|c|c|c|c|c|}
\hline & \multicolumn{4}{|c|}{ Metáforas Corpóreas } & \\
\hline & Orientacionais & & & Ontológicas & \\
\hline Experienciais & Física & Socio-Cultural & Substâncias & Entidades & Metonímias \\
\hline $\begin{array}{l}\text { Metáforas relacionadas à } \\
\text { nossa condição de corpo } \\
\text { interagindo com } 0 \\
\text { ambiente }\end{array}$ & $\begin{array}{l}\text { Metáforas relacionadas à } \\
\text { nossa experiência com o } \\
\text { ambiente e suas restrições } \\
\text { físicas }\end{array}$ & $\begin{array}{l}\text { Metáforas relacionadas à } \\
\text { nossa experiência com a } \\
\text { sociedade e cultura }\end{array}$ & $\begin{array}{l}\text { Metáforas relacionadas à } \\
\text { nosso conhecimento de } \\
\text { substâncias }\end{array}$ & $\begin{array}{l}\text { Metáforas relacionadas à } \\
\text { nossa experiência com } \\
\text { objetos e "coisas" }\end{array}$ & $\begin{array}{l}\text { Metáforas Personificadas } \\
\text { em personagens ou } \\
\text { objetos conhecidos. }\end{array}$ \\
\hline $\begin{array}{l}\text { O futuro está à frente, bom } \\
\text { é pra cima, ruim é pra } \\
\text { baixo. }\end{array}$ & $\begin{array}{l}\text { Dificuldades săo pesos da } \\
\text { gravidade, o tempo passa } \\
\text { depressa (velocidade). }\end{array}$ & $\begin{array}{l}\text { O tempo é nosso inimigo, } \\
\text { a vida é um carnaval. }\end{array}$ & $\begin{array}{l}\text { Um discurso mole, uma } \\
\text { pessoa fria, o clima } \\
\text { esquentou. }\end{array}$ & $\begin{array}{l}\text { Limites, fronteiras, estar } \\
\text { cheio ou vazio, densidade, } \\
\text { proximidade. }\end{array}$ & $\begin{array}{l}\text { O tempo é um sanduíche, } \\
\text { o presidente é um rato. }\end{array}$ \\
\hline
\end{tabular}

Como exemplo de correspondência descrita no livro de Lakoff, podemos citar uma metáfora orientacional do grupo de metáforas ligadas à orientação espacial: quando uma pessoa é importante para você, ou na qual se tem confiança, ela é considerada "o seu braço direito". Esta correspondência vem dos gestos e força do braço que fazem do seu lado direito um lugar de rápido reflexo e apoio. Outro exemplo é descrever o inferno como sendo embaixo da terra ou quando se está deprimido fazer referência à direção de se estar "para baixo". Essa correspondência de tristeza, ou de algo negativo vêm da postura da coluna vertebral e com nossa dificuldade ao se abaixar e ter que se levantar. Do contrário se você está para cima, ou se a bolsa de valores está "subindo" isto quer

Figura 1.

Tabela com dois principais grupos de metáforas Orientacionais e Ontológicas. 
dizer que tudo está bem e que se tem uma situação positiva em correspondência com a postura mas também do nosso conhecimento do crescimento dos seres vivos e da posição do sol. $O$ futuro está na nossa frente e o passado ficou para trás também são exemplos que ilustram bem esse conjunto de metáforas ligadas à nossa percepção espacial. Entre outros exemplos de correspondências destacamos também nossa relação com objetos que fazem emergir metáforas ligadas à quantidades, limites, textura e forma de objetos para criar correspondências como "um contrato sólido" ou um "discurso frouxo" o mesmo "um futuro distante" todas esses conceitos e emoções abstratas são atribuídas sensações reais ou experiência com objetos e suas características.

\section{APLICAÇÕES}

Com o surgimento das novas correntes de investigação em interação homem máquina esse modelo de nossa cognição e do nosso uso natural de metáforas emergem novas pistas para a criação de significados para comandos em aplicações abstratas de novos sistemas informáticos como blockchain, internet 
das coisas ou modelagem paramétrica entre outros sistemas que buscam novas soluções em dispositivos e novos modos de interação. Estes estudos de Varella, Lakoff e os modelos propostos nos auxiliam e ao mesmo tempo nos lançam o desafio de traduzir essa experiência corpórea em significados para produzir uma estrutura conceitual necessária para transformar esses novos modelos de nosso raciocínio em ferramentas de design.

Muitos estudos se concentraram no problema de definir problemas de cognição incorporada e enquadrar corretamente o paradigma incorporado (Bakker et al., [s.d.]). Diversas equipes abordam o problema da definição do problema de como enquadrar corretamente e aplicar este paradigma. Dr. Alissa Antle da School of Interactive Arts and Technology, Simon Fraser no Canadá testou a correspondência entre conceitos tais como o movimento corporal e sua proximidade com ideias abstratas relacionadas ao som (pitch, tempo, volume) (Antle et al., 2008) ou relacionado aos conceitos de justiça com o sentido de equilíbrio (Antle et al., 2009a). Em outra pesquisa Markman e Brendl (Markman \& Brendl, 2005) experimentam as correspondências metafóricas entre a noção de distância 'longe-perto' e o conceito de 'bom ou ruim'. Os resultados reforçam a tese de que os conceitos de nossa percepção e atividade motora correspondem a noções abstratas e podem promover a criação de sentido e evocar ações intuitivas quando abordados corretamente. Em seu artigo com o Raymond Gibbs, da Universidade de Santa Cruz na Califórnia, a professora Ana Maria Macedo, do grupo de Grupo de Estudo sobre Linguagem em Pensamento (GELP) da Universidade Federal do Ceará, investiga a compreensão corporificada das pessoas a respeito da metáfora primária DIFICULDADES SÃO PESOS. (Gibbs Jr \& Macedo, 2010)

Em seu artigo "Designing with Metaphors" Michael Hendrix, co-diretor da IDEO Boston descreve ao uso do modelo das metáforas incorporadas como uma ferramenta de análise estética (Hendrix, 2014). Ele exemplifica o uso do quadro conceitual como um 'provocador de criatividade' e uma fonte de conceitos ligados aos componentes perceptivos da cognição para analisar e criar produtos de design. Ele se interessa principalmente por componentes estéticos em design gráfico e de produto como por exemplo o uso genérico de conceitos de 'pesado' ou 'leve' para tipografias, ou para portas de carros e estilos de mobiliário. $\mathrm{O}$ autor ainda exemplifica componentes visuais e seus significados possíveis como a relação entre a velocidade e um produto dinâmico, ou o claro e o escuro para estruturar conceitos como a melancolia ou a alegria.

Outros exemplos de pesquisas atuais de pesquisa buscam atualizar essa relação entre o paradigma corpóreo e sua validação e aplicações em diversos contextos. A pesquisa de (Manches et al., 2020), por exemplo, examinou o papel e as implicações da cognição corpórea para estudantes de cursos em áreas de exatas com foco em matemática e educação científica. A contribuição deste artigo foi de fornecer evidências empíricas para a natureza incorporada dos conceitos 
de computação e assim chamar a atenção para o potencial desta linha de investigação para o campo do ensino de programação. 0 artigo também tenta identificar padrões e variações em como os indivíduos expressam sua compreensão de conceitos abstratos como loops, algoritmos e condicionais por meio de gestos.

Em design e no campo da interação homem-máquina, as ciências cognitivas buscam modelos coerentes que podem descrever e auxiliar pesquisadores a explorar as capacidades humanas de aprender e realizar suas tarefas. Um exemplo clássico foi o conceito de Affordances que foi trazido da teoria do psicólogo James Gibson, sobre a percepção visual, e popularizado por Donald Norman de uma maneira que designers e outros profissionais pudessem compreender e aplicar em seus processos de criação e estudos do usuário. Essa transcrição do termo affordance não se deu sem erros e polêmicas pois toda a vulgarização está sujeita a interpretações simplificadoras e limitações na aplicação dos conceitos originais. Mas os textos de Norman trouxeram para o campo do design uma visão da cognição humana nova e esse esforço de estreitar as distâncias entre áreas do conhecimento faz avançar os domínios de aplicação e os exemplos de inovação em produtos atuais em design de produto e de interfaces digitais. 
Correntes de pesquisa como as interfaces hápticas e teóricos como Paul Dourish (Dourish, 2004), Alan Blackwell (Blackwell, 2006), Iroshi Ishii (Ishii, 2008), Rekimoto (Rekimoto \& Sciammarella, 2000) entre outros defendem que devemos ir além da analogia visual e simbólica clássica (uma folha de papel é um arquivo de texto) como uma solução para traduzir o acesso à informação e sugerem que façamos mais uso de nossa experiência vivida de interação com o mundo real para criarmos novas metáforas de interação. Os autores destacam estas correlações metafóricas como uma fonte de compreensão e de insights e poderia ser usado para construir correspondências e mapeamentos mais significativos em comandos gestuais, em computação tangível e em computação Ubíqua ou com objetos conectados. Esse modelo também pode ser a base e a fonte de novos conjuntos de metáforas visuais fundamentadas em nossos esquemas corporificados para conceitos abstratos dos sistemas computacionais. Trata-se então de capitalizar nossos conhecimentos adquiridos pela ação, como informações para o uso de qualquer sistema. Isso dá origem a interfaces multimodais baseadas em gestos, sons, e outros vetores de informação perceptiva como o gosto por exemplo. O uso deste tipo de diálogo, entre humanos e máquinas, é mais difícil de concretizar e encapsular na forma de componentes de softwares. Seria necessária então de uma "sinestesia semântica" para estabelecer metáforas entre nossos modelos mentais e as informações perceptivas com as quais estamos familiarizados.

Outro exemplo de aplicação e uso de metáforas ligados ao nosso conhecimento e experiência sensível com materiais e objetos são os programas de renderização 3D como Unity 3D (unity.com) ou o. O Unity é um software para produção e prototipagem de ambientes virtuais em 3D. É um sistema voltado sobretudo para a produção de jogos, mas hoje suas funções são desviadas para a criação de uma grande variedade de produtos interativos. Dentre os mecanismos de animação e renderização do programa é possível criar regras de comportamento entre objetos. Na biblioteca física atual da 
podemos encontrar componentes de comportamento ligados à noção de atrito e parâmetros como "materiais físicos", tais como "gelo", "madeira", "metal" ou "borracha". Um objeto que tenha sido instituído como "gelo", por exemplo, vai passar a se comportar de acordo com as regras estabelecidas no ambiente, tais como a gravidade, mas também irão reagir a outros objetos como um bloco de gelo o faria. Portanto, os parâmetros de objetos que constituem a animação procedural em tempo real, tais como atrito, inércia, fragilidade, farão com que um cubo de gelo deslize em uma superfície com padrões escorregadios além de sua consistência ser frágil e quebrável como é a água congelada.

Neste exemplo apresentamos um encapsulamento de funções em uma linguagem de programação em conceitos naturais. Daniel Shiffman é professor do programa Interactive Telecommunications Program da New York University (shiffman.net/about). Ele produziu uma biblioteca de componentes para a plataforma processing baseada no conceito de física observável chamada Nature of Code (natureofcode.com). Ele associou seu interesse em produzir um material estimulante de ensino de programação (tutoriais, biblioteca de exemplos livros e vídeos) e que ensinam a produzir simulações da natureza (forças, vetores entre outras simulações). Tudo isso em uma linguagem voltada para artistas e outros tipos de iniciantes. A iniciativa de Shiffman nos interessou como exemplo de estratégia de encapsulamento de funções em conceitos de metafóricos baseados na nossa experiência com o ambiente de leis Newtonianas como 'fricção' 'elasticidade', 'velocidade', inércia etc. 


\section{EXPERIMENTO COM TAREFAS DIGITAIS E POSSÍVEIS METÁFORAS.}

Nesta seção apresentaremos alguns exemplos selecionados de interfaces e tarefas que foram experimentados durante nossa pesquisa entre 2010 e 2013 no laboratório Cédric do Conservatório de durante entorno das possibilidades de tradução de uso e das metáforas corpóreas.

Um primeiro exemplo genérico dessa abordagem multiplataforma de metáforas corpóreas são as páginas de rolagem vertical e as interfaces descritas como barras laterais de rolagem (figura 2). A partir das barras de rolagem manipuladas por um mouse em computadores desktop, essa metáfora foi naturalmente transferida e adaptada de uma plataforma para outra. Ela foi adaptada aos gestos naturais de dispositivos móveis para rolar uma página para cima ou para baixo para navegar no texto. A técnica tem um retorno visual de rolagem. Seus atributos de velocidade e tração são baseados em noções ingênuas da física, como fricção e inércia. Para enriquecer essa tarefa e suas interfaces tradicionais usamos o conceito de viscosidade para traduzir alguns casos particulares na tarefa de navegar entre páginas: quando por exemplo o usuário realiza a busca por uma palavra no texto; a rolagem do texto se torna mais rápida ou mais lenta, dependendo do número de itens encontrados. A densidade dos resultados aumenta portanto a "viscosidade" da barra de rolagem "freando" o movimento das páginas, facilitando a leitura dos itens ressaltados durante a pesquisa. 


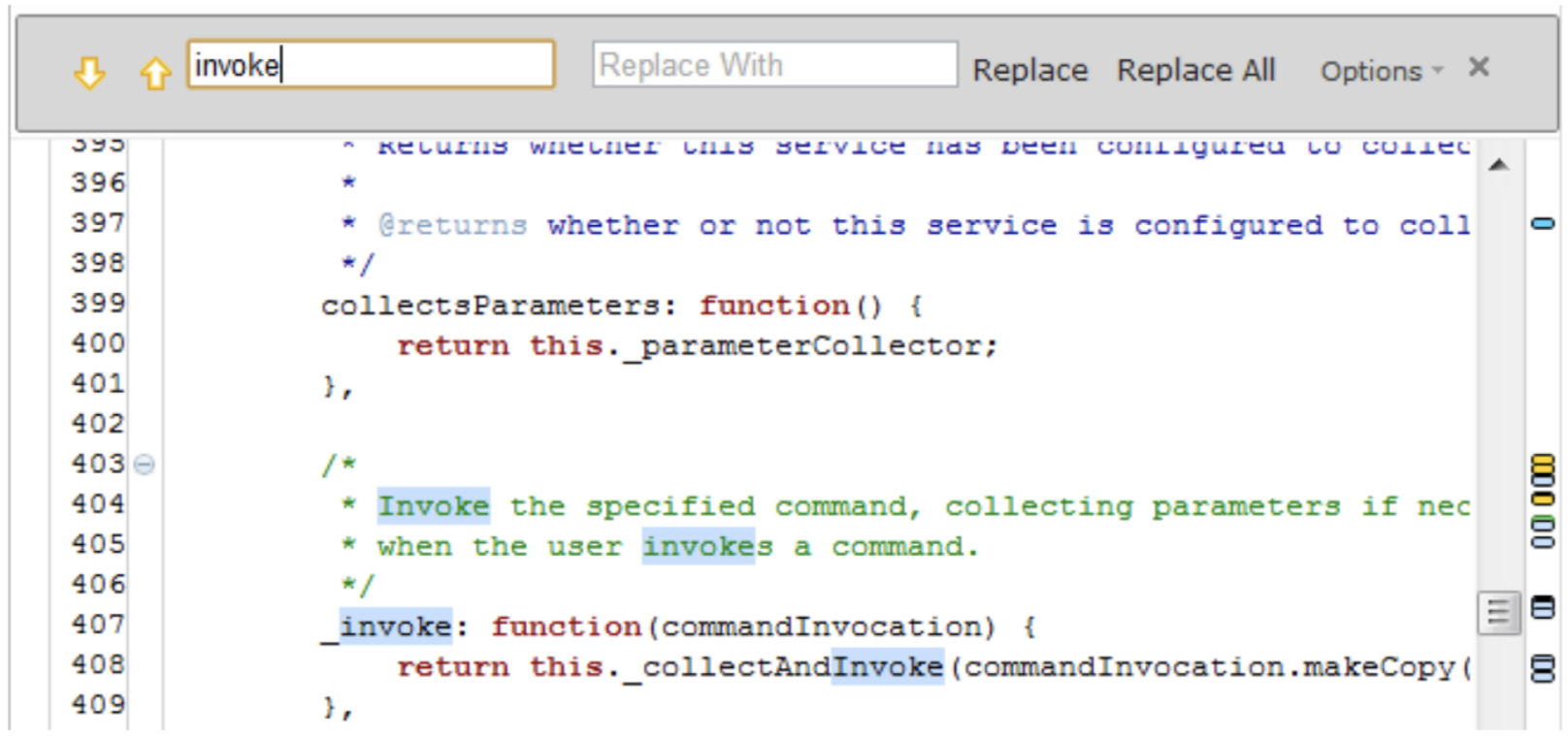

Figura 2

Metáfora ontológica

de viscosidade para

a representação

de buscas em uma

barra de rolagem.

Figura 3

Visualização de filtro

para seleção de músicas

baseado na metáfora

de viscosidade.
Usamos também o conceito de viscosidade para dar diferentes "pesos" aos objetos criando um filtro de seleção e avaliação de músicas (figura 3). As músicas mais bem avaliadas deslizavam melhor na tela enquanto às que possuíam pior avaliação ficavam presas ao líquido viscoso. Portanto, conforme o usuário arrasta as representações dos arquivos de música, eles se movem em velocidades diferentes, indicando o quão boa a música foi avaliada pela quantidade de fricção ao qual é submetida a representação da música no líquido viscoso e destacando visualmente as melhore ou piores músicas.
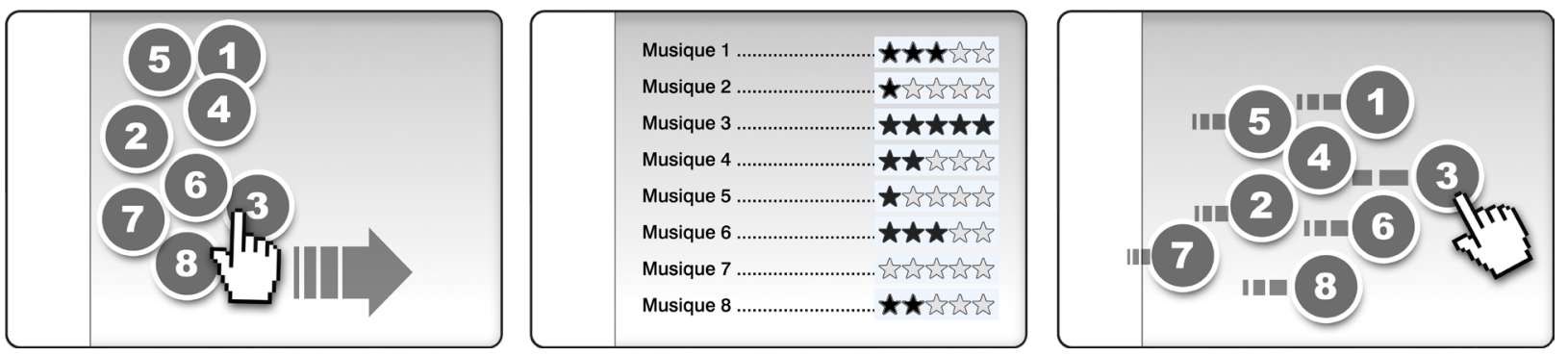


\section{FERRAMENTA DE CRIATIVIDADE}

As investigações dos autores formalizaram, em um projeto, o uso e de uma biblioteca de representações visuais inspiradas no paradigma corpóreo e das metáforas descritas por Lakoff e Johnson. O projeto investiga as formas de enriquecer as ferramentas utilizadas em processos de design e plataformas de prototipagem com o uso de novas metáforas inspiradas dos componentes físicos, gestuais e culturais (sociais) da classificação de Lakoff \& Johnson. Nós propomos uma ferramenta sob a forma de cartas físicas que apresentam cada uma das metáforas corpóreas e dos grupos de metáforas proposto por Lakoff \& Johnson. A disponibilização de forma física dessas metáforas expande a capacidade de comunicação e ação em fases de projeto e ideação em equipes compostas de profissionais heterogêneos ampliando a capacidade proposital contribuindo em agregar competências nos momentos de brainstorm e geração de alternativas e posteriormente na implementação em fases de prototipagem.

A biblioteca foi transformada em uma ferramenta sob a forma de fluxogramas e cartas (figura 4) que representam e traduzem processos cognitivos abstratos em conceitos facilmente assimiláveis e utilizáveis durante as fases de geração de alternativas para enriquecer as ferramentas utilizadas em métodos de design.

Além de auxiliar nas fases de prototipagem a pesquisa também estuda como o uso desta biblioteca de metáforas pode auxiliar na meIhor apropriação deste modelo cognitivo por equipes de designers, artistas e engenheiros. 


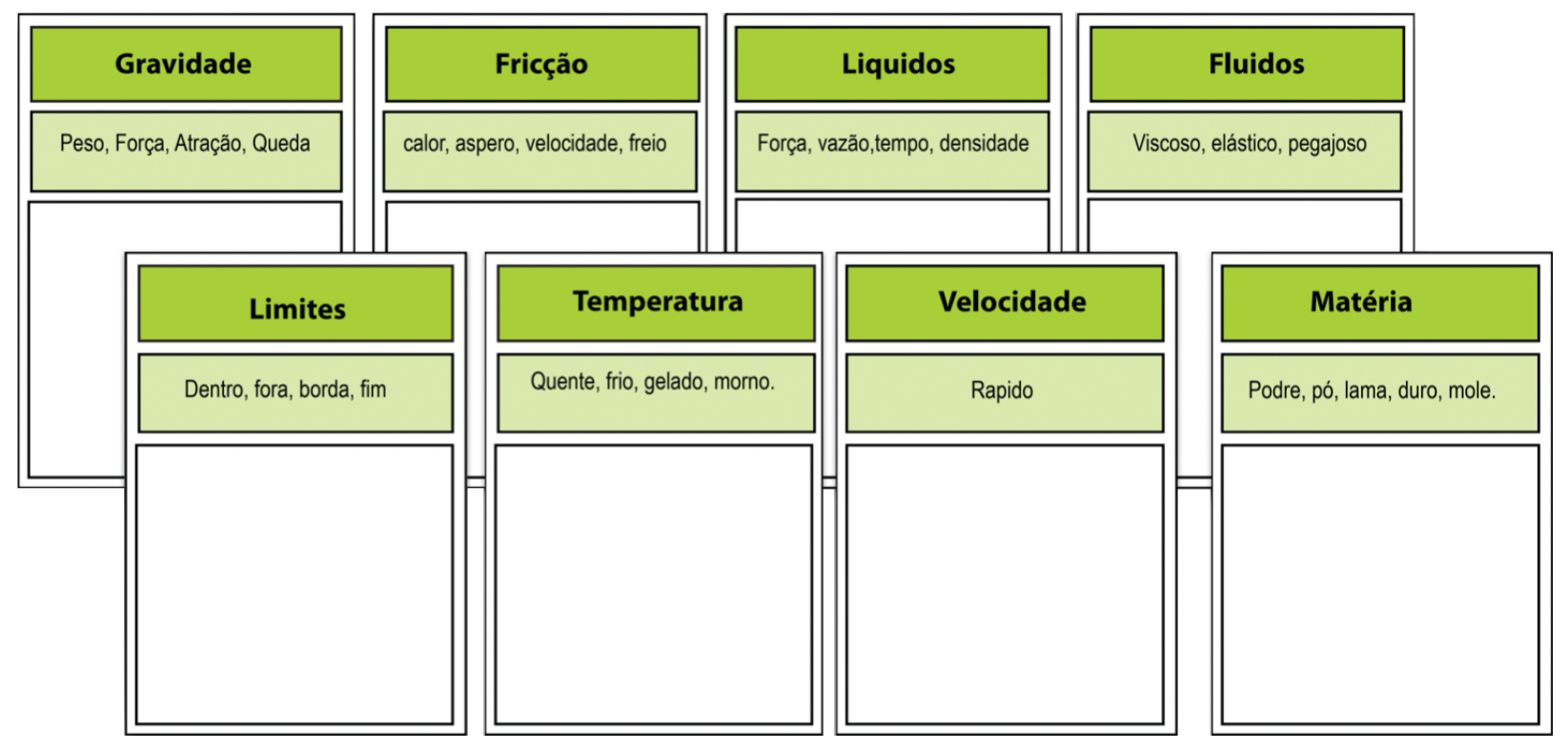

Figura 4

Cartas representando as metáforas conceituais

e a suas descrições com espaços para tomar notas.
Como experimento prático de uso das metáforas, realizamos workshops com alunos das aulas técnicas do colégio Cícero Dias para tentar entender como os usuários poderiam se apropriar dos diferentes conjuntos de metáforas oferecidos. $\mathrm{Na}$ época da pesquisa os alunos do colégio tinham como tarefa dentro, do curso técnico, a criação de jogos eletrônicos em UNITY3D. Alunos da área de design gráfico estivam, neste momento particular, em contacto direto com os programadores. Queríamos que eles pudessem tirar proveito de uma lista de metáforas possíveis para fornecer aos programadores ideias de interface mais ricas. Primeiro mostramos o fluxograma de metáforas de conceitos metafóricos que eles acharam imprecisos porque eram densos e difíceis de definir. Em seguida, reduzimos o número de conceitos propostos, pedindo-lhes que apontassem uma série de conceitos que poderiam fazer sentido para eles em seu projeto. Eles acabaram listando um grande número deles sem muito impacto prático em suas possíveis implementações. Em uma nova estratégia, pegamos os mecanismos e interfaces que já haviam sido implementados e pedimos para fazerem correspondência a conceitos metafóricos. Pedimos em seguida que preenchessem uma lista de objetos do jogo, como o assunto do jogo ou as principais ações que o jogador deveria realizar. Apresentamos as metáforas sob forma de cartas para que eles em seguida pudessem associar a este último exercício. As cartas físicas eram difíceis de se 
manipular pois havia muitas, no entanto elas continham mais detalhes e explicações sobre cada metáfora. Esse exercício os motivou e os alunos acabaram geraram novas ideias de aparências gráficas e possíveis melhorias de suas ideias iniciais graças às cartas que agora demoravam mais nas mãos dos alunos permitindo que eles refletissem mais sobre aquela metáfora específica.

Em outro contexto aplicamos uma entrevista piloto com um professor de programação e especialista em motor UNITY do colégio. As primeiras apresentações das metáforas sob forma de fluxograma e cartas resultaram em resultados muito superficiais. Por exemplo, ele fez a conexão entre a metáfora "limites" e as bordas da tela. À medida que ia descobrindo as outras metáforas e, depois de minha insistência para que ele descrevesse com mais detalhes sua atividade e seu cotidiano, acabou encontrando exemplos de metáforas que faziam sentido para ele explicar diferentes conceitos abstratos apresentados durante a aula. Ao fazer um exercício espontâneo de diferenciar os conceitos de velocidade para o comportamento de objetos como um carro de corrida, ele acabou propondo o termo "agressivo". Este termo é uma metáfora de orientação que poderia estruturar diversos comportamentos a partir de informações sensório-motoras, principalmente visuais (cor vermelha, movimentos rápidos e determinados, conexões incessantes e repetidas). Essa metáfora poderia muito bem fazer parte de um conjunto de scripts de animação, por exemplo. A seguir, indiquei ao professor que esse termo é uma boa proposição ele então passou a ter mais confiança em criar outras propostas interessantes e coerentes com as metáforas e modelo cognitivo.

\section{CONCLUSÕES}

Acreditamos que construir um diálogo entre teoria e aplicação dos conceitos de cognição corpóreas pode ajudar a fornecer conteúdo de discussão para uma estrutura conceitual robusta capaz de nutrir a comunidade de desenvolvedores com soluções estéticas, ideias inovadoras e componentes de software genéricos e modulares. Isso daria aos designers ferramentas acessíveis, poderosas e consistentes com o futuro das interfaces digitais. O futuro deste trabalho consistiria na implementação de uma versão funcional de uma biblioteca de componentes de interação assim como novas ferramentas de prototipagem de interfaces baseados nesses componentes inspirados do paradigma da cognição corpórea. 


\section{BIBLIOGRAFIA}

Amin, T. G., Jeppsson, F., \& Haglund,

J. (2015). Conceptual Metaphor and

Embodied Cognition in Science Learning:

Introduction to special issue. International

Journal of Science Education, 37(5-6),

745-758.

Anderson, M. L. (2007). Chapter Five How

to Study the Mind: An Introduction to

Embodied Cognition Michael L. Anderson.

Brain development in learning environments:

Embodied and perceptual advancements, 65.

Antle, A., Corness, G., \& Droumeva, M.

(2009a). Springboard: Exploring embodi-

ment, balance and social justice. In CHI'O9

Extended Abstracts on Human Factors in

Computing Systems (p. 3961-3966).

Antle, A., Corness, G., \& Droumeva, M.

(2009b). What the body knows: Exploring the benefits of embodied metaphors in hybrid physical digital environments. Interacting with Computers, 21(1-2), 66-75.

Antle, A., Droumeva, M., \& Corness, G.

(2008). Playing with the sound maker: Do embodied metaphors help children learn?

Proceedings of the 7th international conference on Interaction design and children, 178-185.

Bakker, S., van den Hoven, E., \& Antle, A. N. ([s.d.]). Embodied metaphors in tangible interaction design.

Blackwell, A. (2006). The reification of metaphor as a design tool. ACM Transactions 
on Computer-Human Interaction (TOCHI), 13(4), 490-530.

Buron, V. (2014). Penser en action. In Le cerveau et la pensée: Vol. ze éd. (p. 368-373). Éditions Sciences Humaines; Cairn.info.

Dongo, A. (1995). Sobre as raízes do pensamento e da linguagem: Vygotsky e Piaget. Cadernos de Pesquisa, 92, 26-37.

Dortier, J.-F. (2010, dezembro 23). Cognition incarnée: À quoi ressemble l'idée de chien. La quatrièeme question. http://www.dortier. $\mathrm{fr} /$ cognition-incarnee-a-quoi-ressemble-lidee-de-chien/

Dortier, J.-F. (Org.). (2011). Le cerveau et la pensée: Le nouvel âge des sciences cognitives. Sciences Humaines.

Dourish, P. (2004). Where the action is: The foundations of embodied interaction. MIT press.

Farina, M. (2020). Embodied cognition: Dimensions, domains and applications. Adaptive Behavior, 105971232091296.

Fodor, J. A. (1975). The language of thought (Vol. 5). Harvard university press.

Fodor, J. A. (2001). The mind doesn't work that way: The scope and limits of computational psychology. MIT press.

Gibbs Jr, R. W., \& Macedo, A. C. P. S. de. (2010). Metaphor and embodied cognition. DELTA: Documentação de Estudos em Lingüística Teórica e Aplicada, 26(SPE), 679-700.

Gibson, J. (1979). The ecological approach to visual perception Boston: Houghton Mifling, c1979.

Hendrix, M. (2014). (video): 'Let's Get Physical', talk at Creative Mornings. http://panelpicker.sxsw.com/vote/21154.

Hurtienne, J., \& Israel, J. H. (2007). Image schemas and their metaphorical extensions: Intuitive patterns for tangible interaction. Proceedings of the 1st international conference on Tangible and embedded interaction, 127-134.

Ishii, H. (2008). Tangible bits: Beyond pixels. Proceedings of the 2nd 
international conference on Tangible and embedded interaction, xv-xxv.

Lakoff, G., \& Johnson, M. (1980). Metaphors we live by. University of Chicago Press.

Manches, A., McKenna, P. E., Rajendran, G., \& Robertson, J. (2020). Identifying embodied metaphors for computing education. Computers in Human Behavior, 105, 105859.

Markman, A. B., \& Brendl, C. M. (2005). Constraining theories of embodied cognition. Psychological science, 16(1), 6-10.

Merleau-Ponty, M. (1976). Phénoménologie de la perception. Gallimard.

Rekimoto, J., \& Sciammarella, E. (2000). ToolStone: Effective use of the physical manipulation vocabularies of input devices. Proceedings of the 13th annual ACM symposium on User interface software and technology, 109-117.

Richelle, M., Requin, J., \& Robert, M. (Orgs.). (1994). Traité de psychologie expérimentale (Vol. 1). Presses Universitaires de France (PUF).

Shapiro, L., \& Stolz, S. A. (2019). Embodied cognition and its significance for education. Theory and Research in Education, 17(1), 19-39.

Varela, F. J., Thompson, E., \& Rosch, E. (1992). The embodied mind: Cognitive science and human experience. The MIT Press. 